\title{
Effects of Thyrotropin upon Thyroidal Iodide; Studies Using Thyroid Venous Cannulation and Two Radioiodine Isotopes*
}

\author{
G. H. Isaacs, $\dagger$ J. C. Athans, and I. N. Rosenberg $\ddagger$ \\ (From the Fifth and Sixth [Boston University] Medical Services and the Third [Boston Uni- \\ versity] Surgical Service, Boston City Hospital, and the Department of Medicine and \\ Surgery, Boston University School of Medicine, Boston, Mass.)
}

Studies in dogs have indicated that after the injection of thyrotropin (TSH) there is an enhanced release into thyroid venous blood of inorganic iodine in addition to the expected secretion of hormonal iodine $(1,2)$. Plasma iodide that has been newly accumulated by the thyroid iodide "trap" and still exists in the gland in inorganic form (transported iodide) does not appear to be the major source of the iodide released after TSH stimulation. The published data [reviewed in (3)] suggest that the iodide so released is produced within the gland and is derived from deiodination of glandular organic compounds.

However, a release of transported iodide into thyroid venous blood after TSH administration also has been demonstrated by studies in which organic binding of iodide was blocked $(4,5)$. The mechanism for the release of transported iodide and its relationship to the generation and release of iodide produced within the gland from organic precursors remain unresolved. It has been suggested (5) that the effect of TSH upon the release of transported iodide may be a consequence of the formation of iodide from glandular organic stores.

The purpose of this report is to present data that provide more precise characterization of the effect of TSH upon glandular iodide release and of the

* Submitted for publication October 22, 1965 ; accepted January 25, 1966.

Supported by research grants A-2585 and A-5589 from the National Institute of Arthritis and Metabolic Diseases.

Presented in part at the Forty-fifth Meeting of the Endocrine Society, June 13, 1963.

† Postdoctoral research fellow, National Institute of Arthritis and Metabolic Diseases.

$¥$ Address requests for reprints to Dr. I. N. Rosenberg, Boston City Hospital, 818 Harrison Ave., Boston, Mass. 02118. relationship of iodide derived from intraglandular organic stores to that newly accumulated from the circulation. Experiments were performed in which these two sources of glandular iodide were individually labeled in the same animal with different radioiodine isotopes whose flux between thyroid and circulation was estimated from differences between the radioiodide concentrations of arterial and thyroid venous plasma. Related studies on the acute effect of TSH on unidirectional (blood to thyroid) radioiodide clearance and on the sensitivity of iodide release to exogenous TSH stimulation are also reported.

\section{Methods}

Pentobarbital-anesthetized male mongrel dogs, weighing 30 to 50 pounds, were used in all experiments. The inferior thyroid vein of one lobe was cannulated, and continuous serial samples of thyroid venous blood were obtained by methods previously reported (1). The duration of each sampling period was usually 4 to 6 minutes; this was reduced to 2 to 3 minutes in the clearance experiments. Femoral arterial blood was drawn at the midpoint of each venous sample. Intravenous injections were given through a femoral vein cannula.

Radioactivity measurements were made with a scintillation well counter and spectrometer. All samples were counted at a final volume of $1.0 \mathrm{ml}$. Separate ${ }^{125} \mathrm{I}$ and ${ }^{181} \mathrm{I}$ standards were made from suitable dilutions of the same isotope solutions administered to the animals. The activity present at each of two different energy levels was determined for each plasma sample and isotope standard with spectrometer window widths of 22.5 to $41 \mathrm{kev}$ (low setting) and 100 to $430 \mathrm{kev}$ (high setting). The high setting includes the main energies of ${ }^{121} \mathrm{I}$ and excludes all but approximately $0.03 \%$ of the ${ }^{125} \mathrm{I}$ emissions. The low setting includes the ${ }^{125} \mathrm{I}$ energies but also admits emissions from ${ }^{182} \mathrm{I}$. Approximately $8.5 \%$ of the ${ }^{181} \mathrm{I}$ activity detected at the high setting was counted at the low setting. The correction factor by which the observed ${ }^{105} \mathrm{I}$ count was adjusted to compensate for this ${ }^{181} \mathrm{I}$ "overlap" was obtained from the ratio of counts given by the ${ }^{181} \mathrm{I}$ standard at each spectrometer setting. Corrected ${ }^{125} \mathrm{I}$ count of 
sample $=$ sample count at low setting $-($ sample count at high setting $\times{ }^{131} \mathrm{I}$ standard count at low setting/139 I standard count at high setting).

Over-all counting efficiency was approximately $70 \%$ for ${ }^{120} \mathrm{I}$ and $40 \%$ for ${ }^{121} \mathrm{I}$. Isotope concentrations were expressed as a per cent of the injected dose per liter of plasma (\% D per L).

\section{Experimental design}

Three groups of experiments were performed.

I. Effect of TSH on glandular radioiodide release and on isotopic composition $\left({ }^{125} I /{ }^{181} I\right)$ of radioiodide in the thyroidal iodide trap. Three to 7 days before surgery, the animals were given a parenteral dose of carrier-free ${ }^{101}$ I ( 300 to $400 \mu \mathrm{c}$ ) ; 2 hours before the time of thyroid venous cannulation, methimazole $(100 \mathrm{mg})$ was given intravenously followed by $50 \mu \mathrm{c}$ of carrier-free ${ }^{120} \mathrm{I}$. Circulating iodide was thereby labeled predominantly with ${ }^{125} \mathrm{I}$ and glandular organic iodine stores exclusively with ${ }^{181} \mathrm{I}$. Concentrations of both isotopes in whole plasma and of ${ }^{181} \mathrm{I}$ in trichloroacetic acid (TCA) precipitates were determined; ${ }^{120} \mathrm{I}$ and TCA-soluble ${ }^{181} \mathrm{I}$ were considered to be inorganic iodine. A) Two dogs. After collection of two or more control blood samples, the animals were given 10 U.S.P. U of TSH 1 intravenously, and 30 to 80 minutes later, $200 \mathrm{mg}$ of $\mathrm{NaClO}_{4}$. B) Eleven dogs. To determine the isotope ratio ${ }^{125} \mathrm{I} /{ }^{2 s} \mathrm{I}$ of iodide in the thyroid iodide trap, we gave small injections of $\mathrm{NaClO}_{4}$ ( 1 or $2 \mathrm{mg}$ ) or sodium thiocyanate (3 or $6 \mathrm{mg}$ ) before TSH and/or once or twice after TSH in addition to the final large dose of perchlorate. The quantity of iodide discharged as a result of the injections was taken to be the increase in the veno-arterial difference in the sampling period immediately after thiocyanate or perchlorate over that of the sampling period immediately preceding. In three of these experiments, multiple small thiocyanate injections were given to dogs not receiving $\mathrm{TSH}$. C) Two dogs. A procedure identical to that described above in $A$ was performed, except that stable iodide carrier ( 5 and $50 \mathrm{mg}$, respectively) was given with the ${ }^{125} \mathrm{I}$ label.

The experimental conditions in group I (as well as group III) were such that iodide- ${ }^{121}$ I released from the gland represented both transported iodide and iodide generated within the gland. The release of iodide- ${ }^{181} \mathrm{I}$ not accounted for by release of transported iodide (and therefore presumably indicating release of iodide produced in the gland) was calculated by subtracting from the observed iodide- ${ }^{182} \mathrm{I}$ release the transported iodide- ${ }^{181} \mathrm{I}$ release to be expected from the observed iodide- ${ }^{120} \mathrm{I}$ release and the ${ }^{181} \mathrm{I} /{ }^{125} \mathrm{I}$ ratio of arterial inorganic iodine. Released ${ }^{181} \mathrm{I}_{D^{-}}=$iodide released from the gland that originated from deiodination of organic precursors. $\mathrm{R}=\mathrm{ex}-$ traction ratio for ${ }^{125} \mathrm{I}^{-}=\left({ }^{120} \mathrm{I}_{\Delta^{-}}-{ }^{120} \mathrm{I}_{V^{-}}\right) /{ }^{205} \mathrm{I}_{\Delta^{-}}$. Released ${ }^{181} \mathrm{I}_{\mathrm{D}^{-}}=$observed ${ }^{181} \mathrm{I}^{-}$release - transported ${ }^{181} \mathrm{I}^{-}$release $=$ $\left({ }^{131} I_{\nabla^{-}}-{ }^{131} I_{\Delta^{-}}\right)-\left[\left({ }^{120} I_{\nabla^{-}}-{ }^{125} I_{\Delta^{-}}\right) \times\left({ }^{181} I_{\Delta}{ }^{-} /{ }^{125} I_{\Delta^{-}}\right)\right]=$ ${ }^{181} \mathrm{I}_{\nabla^{-}}-{ }^{181} \mathrm{I}_{\Delta^{-}}+\mathrm{R} \times{ }^{181} \mathrm{I}_{\Delta^{-}}$. Released ${ }^{181} \mathrm{I}_{D^{-}}={ }^{181} \mathrm{I}_{\nabla^{-}}-$ ${ }^{181} \mathrm{I}_{\mathbf{A}^{-}}(1-\mathrm{R})$ in units of per cent dose per liter. The

1 The TSH used in all experiments was Thytropar, Armour Pharmaceutical Co., Kankakee, Ill. subscripts $\mathrm{A}$ and $\mathrm{V}$ indicate arterial and thyroid venous plasma, respectively.

D) In a single experiment utilizing only ${ }^{191} \mathrm{I}$, an anesthetized dog was given $100 \mathrm{mg}$ of methimazole intravenously followed by the tracer dose of ${ }^{181} \mathrm{I}$. After 2 hours, to allow for thyroid-serum isotope equilibrium, we determined the position of one thyroid lobe as accurately as possible with a scintiscanner. The neck was then covered by a $0.6-\mathrm{cm}$ thick lead plate with a $2.5-\mathrm{cm}$ circular opening centered over the lobe. A scintillation detector was, in turn, placed over the opening.

Repeated counts were taken for a control period of 27 minutes, for 51 minutes after the intravenous injection of $10 \mathrm{U}$ of $\mathrm{TSH}$, and for 48 minutes after the injection of $200 \mathrm{mg}$ of $\mathrm{NaClO}_{4}$. Counts were corrected for room and body background.

II. Effect of TSH on unidirectional clearance of circulating iodide by the thyroid (binding blocked). A) Seven dogs. Dogs which had received no radioiodine were given $100 \mathrm{mg}$ of methimazole intravenously 2 hours before cannulation. After thyroid venous cannulation, a tracer dose of either ${ }^{181} \mathrm{I}$ or ${ }^{125} \mathrm{I}$ was rapidly injected intravenously, and serial blood samples were collected from the moment of injection. TSH was then given intravenously; 15 to 30 minutes later the second iodide isotope was injected, and blood samples were collected in the same manner as after the first isotope injection. The net thyroidal iodide clearance for each isotope was calculated for each collection period from the product of the observed extraction ratio and the thyroid venous flow rate. The average of the observed clearances (usually three) determined during the first 10 minutes after isotope injection was considered to be an approximation of the unidirectional clearance for each isotope. B) Six dogs. In a group of control experiments, the same procedure was followed, but saline was given in place of TSH.

III. Threshold dose-response relationship of TSH administration to thyroidal iodine release (four dogs). Dogs were first labeled with ${ }^{131} \mathrm{I}$ and then given methimazole and ${ }^{120} \mathrm{I}$ as described for group I experiments. Doses of $\mathrm{TSH}$ in increasing amounts, ranging from 0.001 to 15.0 $\mathrm{U}$, were given intravenously at approximately 30 -minute intervals, and the magnitude of the subsequent release, if any, of protein-bound iodine- ${ }^{181} \mathrm{I},{ }^{131} \mathrm{I}_{D}^{-}$, and ${ }^{1200} \mathrm{I}^{-}$was noted.

\section{Results}

\section{Group I}

In the experiments of group I, the two sources of glandular iodide were individually labeled with different radioiodide isotopes in such a manner that ${ }^{125} \mathrm{I}$ (together with a small part of the ${ }^{131} \mathrm{I}$ ) labeled transported iodide and ${ }^{131} \mathrm{I}$ labeled iodide produced from intraglandular organic precursors.

Group IA. One of the experiments is illustrated in Figure 1. Within 2 hours after the administration of methimazole together with ${ }^{125} \mathrm{I}$, 


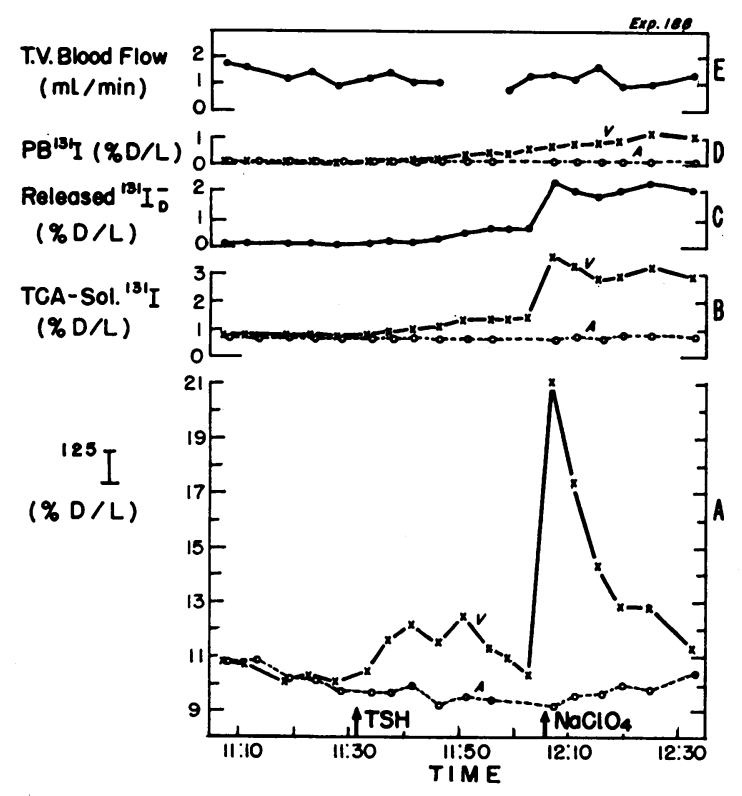

Fig. 1. EFFect of thyrotropin (TSH) AND PERCHLORATE ON RELEASE OF INORGANIC AND PROTEIN-BOUND IODINE ( $\mathrm{PB}^{131} \mathrm{I}$ ) FROM DOG THYROID. A tracer dose of ${ }^{131} \mathrm{I}$ was given 5 days before surgery. Methimazole (100 $\mathrm{mg}$ ) followed by a tracer dose of ${ }^{125} \mathrm{I}$ was given 2 hours before the time of thyroid venous cannulation.

In this Figure and in Figures 2, 3, and 4, the following notations apply: All injections were given intravenously at the times indicated by arrows. The doses of TSH and $\mathrm{NaClO}_{4}$ were $10 \mathrm{U}$ and $200 \mathrm{mg}$, respectively. Panels $\mathrm{A}, \mathrm{B}$, and $\mathrm{D}$ indicate observed plasma concentrations; crosses with solid lines indicate thyroid venous (V) plasma, and open circles with broken lines indicate arterial (A) plasma. The curve in panel $\mathrm{C}$ is calculated from the observed data (see Methods) and indicates release of radioiodide presumed to have been produced in the gland from organic precursors $\left({ }^{181} \mathrm{I}_{\mathrm{D}}{ }^{-}\right)$. Panel $\mathrm{E}$ shows thyroid venous (TV) blood flow rate. TCA = trichloroacetic acid; $\% \mathrm{D} / \mathrm{L}=$ per cent dose per liter. [Reproduced from (3) with permission of the Academic Press.]

isotopic equilibration of iodide between thyroid and circulation had occurred, as is indicated by the negligible difference in the ${ }^{125} \mathrm{I}^{-}$concentration of arterial and thyroid venous plasma during the control period. After the injection of $10 \mathrm{U}$ of $\mathrm{TSH}$, a sustained release of ${ }^{131} \mathrm{I}_{\mathrm{D}^{-}}$occurred, first discernible 5 to 10 minutes after TSH, and was paralleled by a similar rise in protein-bound- ${ }^{131} \mathrm{I}$. An enhanced release of ${ }^{125} \mathrm{I}^{-}$also occurred, beginning less than 5 minutes after TSH and initially rising at a more rapid rate than the ${ }^{131} \mathrm{I}_{\mathbf{D}}$ - release. Iodide- ${ }^{-125} \mathrm{I}$ release reached a peak 20 to 25 minutes after TSH and then began to decline, approaching but not yet reaching the concentration in arterial blood 34 minutes after TSH, whereas the sustained release of ${ }^{131} \mathrm{I}_{\mathbf{D}^{-}}$continued. When $\mathrm{NaClO}_{4}$ was given, there was a substantial discharge not only of ${ }^{125} \mathrm{I}^{-}$but also of ${ }^{131} \mathrm{I}_{\mathrm{D}^{-}}$, suggesting that the latter had been accumulating in the thyroidal iodide trap. The quantity of ${ }^{125} \mathrm{I}^{-}$discharged after $\mathrm{TSH}$ was approximately $50 \%$ of that subsequently discharged by perchlorate. This pattern of response was similar in all experiments in group $I$.

Group IB. To study the effect of TSH on the composition, in terms of its origins, of the iodide in the trap, we gave small injections of thiocyanate or perchlorate before and at various times after $\mathrm{TSH}$ to cause a discharge of part of the iodide being retained by the gland. Similar experiments were also performed without the administration of TSH. Figures 2 and 3 , respectively, illustrate each type of experiment. Thyrotropin induced the same pattern of release of ${ }^{125} \mathrm{I}^{-}$and ${ }^{131} \mathrm{I}^{-}$(Figure 2 ) as seen in group IA experiments; in addition, each injection of thiocyanate produced a small discharge of iodide seen as peaks superimposed upon these curves. As indicated by the curve for released ${ }^{131} \mathrm{I}_{\mathbf{D}^{-}}$, only after $\mathrm{TSH}$ did thiocyanate lead to an appreciable discharge of iodide derived from organic precursors.

When TSH was omitted (Figure 3), partial ejections of both isotopes again were seen. In this case, however, the ${ }^{131} \mathrm{I}^{-}$discharged by thiocyanate and perchlorate could be accounted for almost entirely by iodide transported from the circulation, resulting in the flat curve for ${ }^{131} \mathrm{I}_{\mathbf{D}}{ }^{-}$.

The ratio of ${ }^{125} \mathrm{I} /{ }^{131} \mathrm{I}$ in the iodide discharged as a consequence of thiocyanate or perchlorate injection was determined and, for purposes of comparison, was expressed as a fraction of the same ratio in the arterial blood of the corresponding collection period. Under the conditions of the experiments in this group, if no iodide derived from organic precursors were present in the glandular iodide readily exchangeable with the plasma iodide, the ratio of ${ }^{125} \mathrm{I} /{ }^{131} \mathrm{I}$ in iodide discharged by thiocyanate or perchlorate would be identical to that in arterial blood. The observed values are shown in Table I.

In seven experiments, the ratio of ${ }^{125} \mathrm{I} /{ }^{131} \mathrm{I}$ in discharged iodide was close to that in arterial blood in unstimulated animals, averaging $0.823 \pm$ 


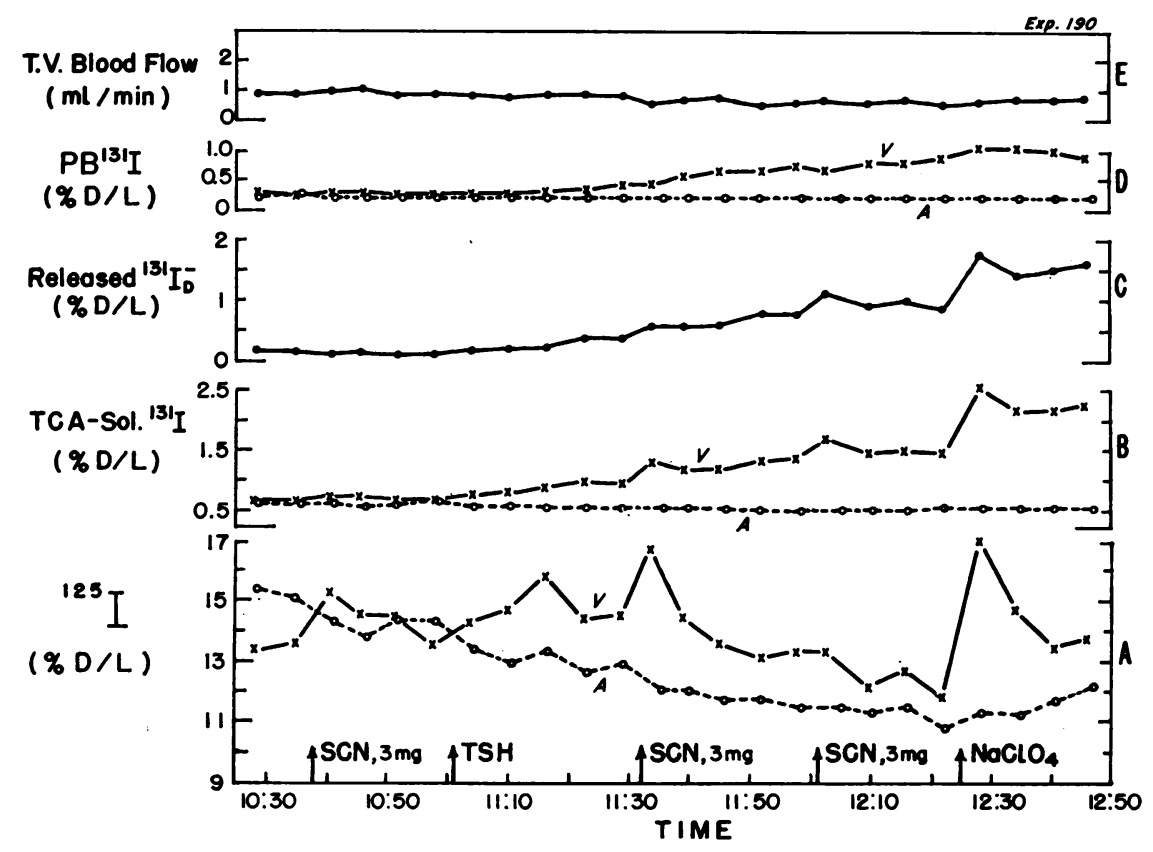

Fig. 2. EFFect of thiocyanate AND PERChLORATE ON RELEASE OF IODIDE FROM THE THYROID BEFORE AND AFTER TSH INJECTION. The tracer dose of ${ }^{191} \mathrm{I}$ was given 5 days before surgery. Methimazole $(100 \mathrm{mg})$ followed by a tracer dose of ${ }^{125} \mathrm{I}$ was given 1.5 hours before thyroid venous cannulation.

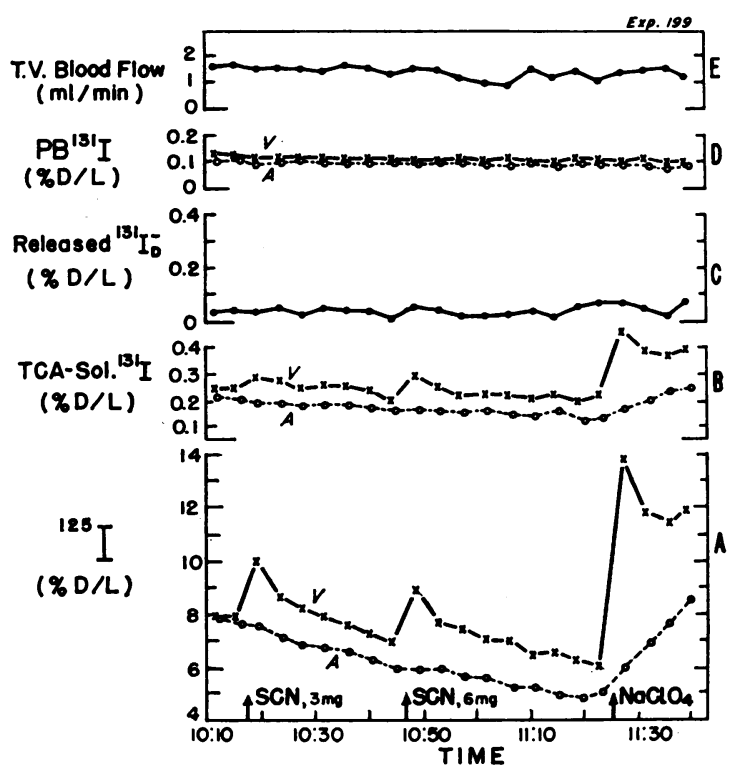

Fig. 3. EFfect of thiocyanate AND Perchlorate on RELEASE OF IODIDE FROM THE THYROID IN THE ABSENCE OF EXOGENOUS TSH STIMULATION. The tracer dose of 181 was given 5 days before surgery. Methimazole $(100 \mathrm{mg})$ followed by a tracer dose of ${ }^{100} \mathrm{I}$ was given 2 hours before thyroid venous cannulation.
0.196 (mean $\pm \mathrm{SEM}$ ) of the arterial value. That this initial value was not $100 \%$ of the arterial ratio suggests that even before the administration of $\mathrm{TSH}$, there was iodide in the trap that originated from organic precursors. Presumably, physiologic levels of thyrotropic activity may be responsible for some iodide formation from intraglandular organic compounds. During the 30- to 45-minute period after TSH injection, there was a fourfold increase in the proportion of ${ }^{131} \mathrm{I}$ present in the discharged iodide, the ${ }^{125} \mathrm{I}^{-} /{ }^{131} \mathrm{I}^{-}$ratio falling to $0.214 \pm 0.072$ of the arterial ratio and remaining at that level in the 45- to 60- and 75- to 90-minute intervals after TSH stimulation. The difference between the mean for each post-TSH period and the pre$\mathrm{TSH}$ period was statistically significant. In three animals not given $\mathrm{TSH}$, the mean isotopic ratio in the discharged iodide was 0.80 of the arterial value initially and was 1.30 and 1.35 of the arterial ratio at times in the course of experiments comparable to the 30- to 45-minute and 45- to 60-minute post-TSH periods in the stimulated animals (Table II).

Group IC. The above data suggested that at least a part of the iodide generated de novo in the 
TABLE I

Isotopic composition $\left({ }^{125} I /{ }^{131} I\right)$ of iodide discharged by thiocyanate-perchlorate before and after TSH injection*

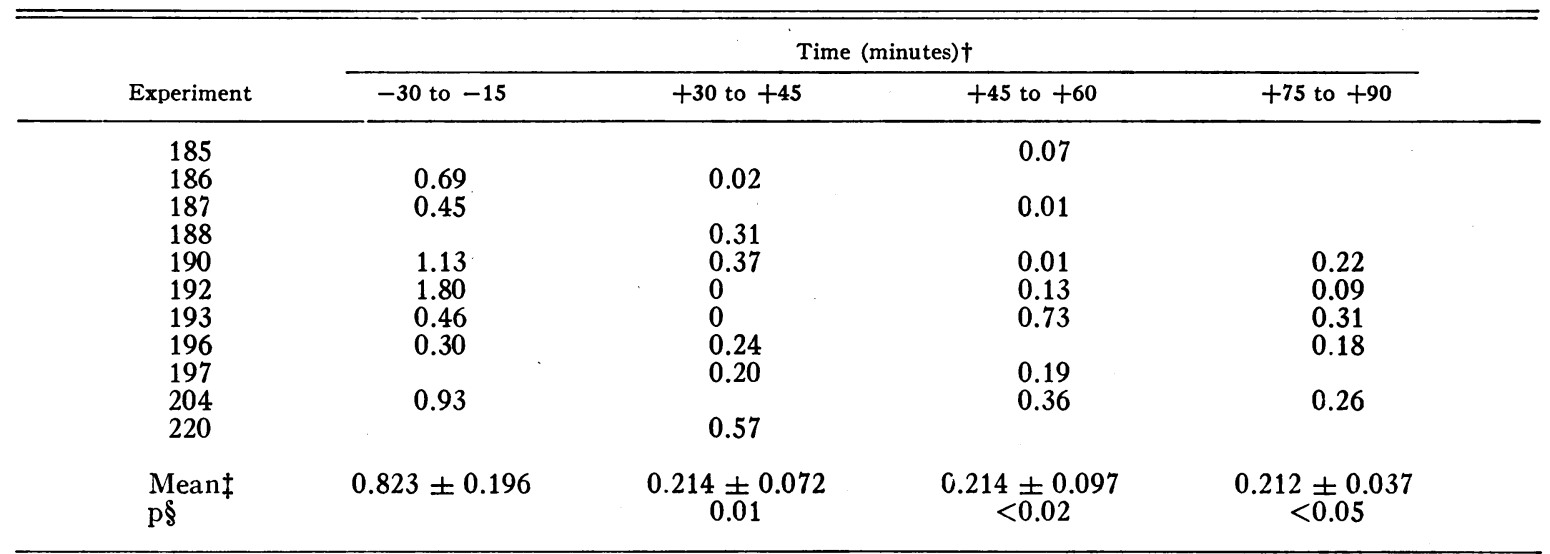
blood.

* Values for ratio of ${ }^{125} \mathrm{I} /{ }^{131} \mathrm{I}$ in discharged iodide are expressed as a fraction of the same ratio for iodide in arterial $\dagger$ Indicates time of thiocyanate or perchlorate injection. Thyrotropin (TSH) injected at time 0 .

$\ddagger$ Mean \pm standard error of the mean.

$\S$ Significance (Student's $t$ test) of the difference between the mean of each post-TSH group and the pre-TSH group.

gland after TSH administration mixed in the gland with iodide transported from the circulation. The experiments in this group were designed to determine whether the increment in intrathyroidal iodide concentration that would result from such an admixture could produce the observed release of ${ }^{125} \mathrm{I}^{-}$. These studies were performed under conditions in which the glandular content of ${ }^{125} \mathrm{I}$-labeled transported iodide was made so large that the quantity of newly formed ${ }^{131} \mathrm{I}^{-}$ labeled iodide mixing with it would not be adequate to enhance significantly glandular $\mathrm{I}^{-}$content and thus would not be expected to change the equilibrium between glandular and circulating iodide. The procedure was identical to that in group

TABLE II

Isotopic composition $\left({ }^{125} I /{ }^{131} I\right)$ of iodide discharged by thiocyanate-perchlorate in unstimulated animals*

\begin{tabular}{ccccc}
\hline \hline & \multicolumn{4}{c}{ Time (minutes) $\dagger$} \\
\cline { 2 - 5 } Experiment & 0 & 15 to 30 & 45 to 60 & 75 to 90 \\
\hline 194 & 0.38 & 0.80 & 1.68 & 0.67 \\
199 & 1.11 & 0.55 & 0.92 & 0.97 \\
224 & 0.91 & & 2.42 \\
Mean & 0.800 & 0.675 & 1.300 & 1.353 \\
\hline
\end{tabular}

* Values for the ratio of ${ }^{126} \mathrm{I} /{ }^{131} \mathrm{I}$ in discharged iodide are expressed as a fraction of the same ratio for iodide in arterial blood.

$\dagger$ Indicates the time of each thiocyanate or perchlorate injection, the first injection occurring at time 0 . No TSH was given.

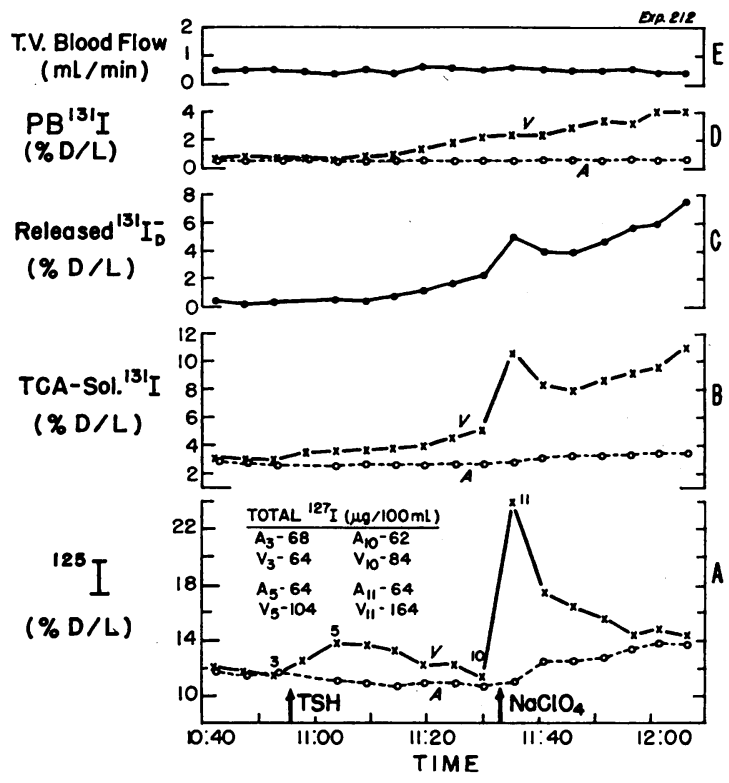

Fig. 4. EFFect of TSH ANd PERChLORATE ON RELEASE OF INORGANIC AND PROTEIN-BOUND IODINE FROM THE THYROID IN THE PRESENCE OF ELEVATED CONCENTRATIONS OF CIRCULATING IODIDE. A tracer dose of ${ }^{181} \mathrm{I}$ was given 4 days before surgery. Methimazole $(100 \mathrm{mg}$ ) followed by a tracer dose of ${ }^{120} \mathrm{I}$ and $5 \mathrm{mg}$ of ${ }^{127} \mathrm{I}$ (as $\mathrm{NaI}$ ) was given 2.5 hours before thyroid venous cannulation. The numerals at points along the curve in panel $\mathrm{A}$ indicate the plasma samples for which stable iodine concentrations are noted in the Table above the curve. The arterial iodine concentrations are approximately ten times those normally seen. 
IA, except that 5 or $50 \mathrm{mg}$ of stable iodide carrier was given with the ${ }^{125} \mathrm{I}$ tracer. The effect of TSH injection on ${ }^{125} \mathrm{I}^{-}$release was similar in both animals. Figure 4 illustrates the results in the animal given the smaller dose of stable $\mathrm{I}^{-}$.

Plasma (and presumably glandular) iodide concentrations at least ten times normal were achieved. However, thyrotropin still led to a substantial release of both ${ }^{125} \mathrm{I}^{-}$and ${ }^{131} \mathrm{I}_{\mathrm{D}^{-}}$, and the release curves were entirely similar to those seen when no carrier was given (compare Figure 4 to Figure 1). The chemically determined iodine values corresponded well to the ${ }^{125} \mathrm{I}^{-}$figures. The ratios of ${ }^{125} \mathrm{I}^{-} /{ }^{131} \mathrm{I}^{-}$in the first sample after perchlorate injection were $53 \%$ (in the experiment in which 5 mg stable $\mathrm{I}^{-}$was given) and $7.4 \%$ (in the experiment in which $50 \mathrm{mg}$ stable $\mathrm{I}^{-}$was given) of the corresponding arterial ratios, suggesting that mixing of transported iodide with iodide produced in the gland had occurred.

Group ID. The enhanced glandular release into thyroid venous blood of transported iodide observed after TSH administration could be shown to be associated with a reduction in the total glandular content of transported radioiodide in the dog, as determined by external neck counting. During the control period, in an animal given methimazole and ${ }^{131}$ I 2 hours earlier, radioactivity remained constant, suggesting that a steady-state thyroid/serum radioiodide concentration gradient ( $\mathrm{T} / \mathrm{S}$ ratio) had been established (Figure 5). Glandular radioactivity began to decline 4 minutes after TSH was injected and during the 51-minute period after TSH decreased to a level of $47 \%$ of the pre-TSH activity. After perchlorate injection, there was a further abrupt decline to the level of body background.

Since organic binding was blocked from the time of isotope administration, the loss of glandular radioactivity must have represented release of transported radioiodide. This was substantiated by the rapid fall of activity to the level of body background when trapping was blocked with perchlorate. It is likely, therefore, that there was a $50 \%$ reduction in the $\mathrm{T} / \mathrm{S}$ ratio in less than 50 minutes after TSH injection.

\section{Group II}

-The release of transported iodide after TSH administration could not be attributed to a change

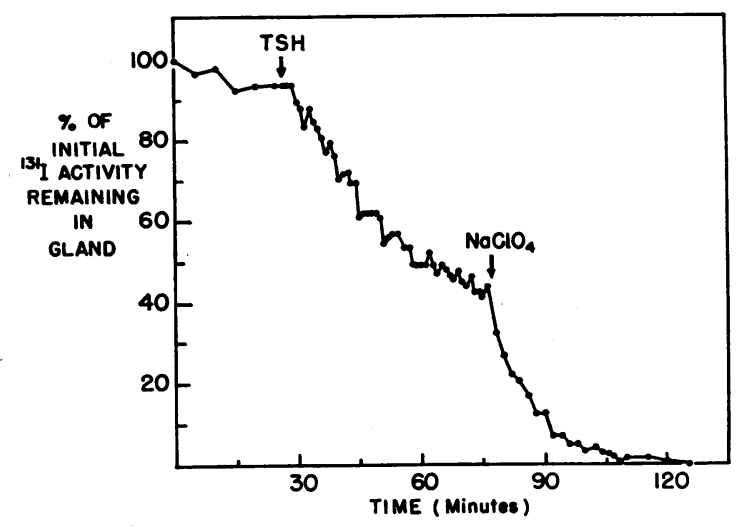

Fig. 5. EFfect of TSH AND PERChlorate oN the LEVEL OF GLANDULAR RADIOACTIVITY (BINDING BLOCKED) AS DETERMINED BY EXTERNAL NECK COUNTING. Methimazole $(100 \mathrm{mg})$ followed by a tracer dose of ${ }^{131} \mathrm{I}$ was given intravenously 2 hours before counting was begun. Counts were corrected for body background. TSH (10 U) and $\mathrm{NaClO}_{4}(200 \mathrm{mg})$ were injected intravenously at the times indicated by arrows.

in the rate at which plasma iodide entered the thyroid. The observed clearance of an injected iodide isotope was determined for the first 10 minutes after the time of injection both before and again 15 to 30 minutes after the injection of either 10 $\mathrm{U}$ of TSH or saline. At short time intervals after isotope injection, the observed clearance of the isotope approximates ${ }^{2}$ the unidirectional (blood to thyroid) clearance (6). The results are shown in Figure 6 and Table III.

There was no significant difference between the initial mean clearance of the TSH and saline control groups. The clearance after saline injection remained virtually identical to the initial clearance value. After TSH injection, there was a $20.9 \%$

2 This estimation of unidirectional clearance with binding blocked can be considered only an approximation of the true value. At short intervals after the injection of the isotope, when thyroid accumulation of radioiodide is still negligible, exchange of radioiodide between circulation and gland may be considered to be one way, from blood to gland (6). However, significant exchange from gland to blood can occur very rapidly, especially when equilibration proceeds at a rapid rate (7). In the dog, equilibration usually requires approximately 2 hours. Nevertheless, in these experiments, the observed clearance in each successive 2- or 3-minute period after isotope injection was lower than in the preceding interval. The mean for those observations made in the first 10 minutes was used in order to compensate for variations in the measured flow rate and the initial incomplete dilution of the isotope. 


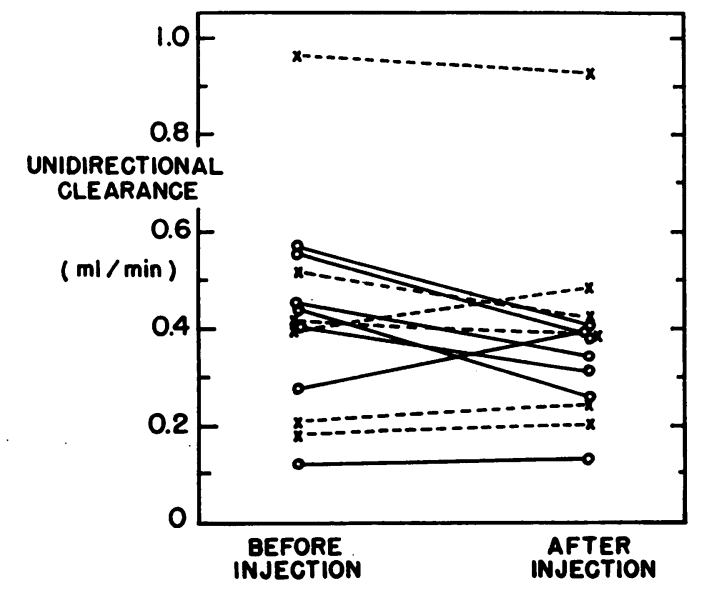

Fig. 6. Estimated PLASMA-TO-THYRoId CLEARANCE BEFORE AND 15 TO 30 MINUTES AFTER INTRAVENOUS INJECTION of TSH (10 U) OR SALINE. Circles with solid lines indicate dogs given TSH; crosses with broken lines indicate saline-injected controls.

fall in mean clearance. The fall in clearance after $\mathrm{TSH}$, however, was not statistically significant $(p>0.2)$, nor was the difference in change in clearance between the TSH and saline groups $(p>0.1)$. Similar results were obtained when clearance was determined for a 3-minute rather than a 10-minute interval after isotope injection.

\section{Group III}

These experiments were performed in an effort to learn whether the effects of $\mathrm{TSH}$ on release of iodide produced in the gland, transported iodide, and protein-bound iodine represent independent, unrelated actions of TSH that might show a difference in sensitivity to administered TSH. In-

TABLE III

Unidirectional clearance by thyroid of circulating radioiodide before and after injection of TSH or saline*

\begin{tabular}{lccc}
\hline \hline & \multicolumn{2}{c}{ Material injected } & TSH- \\
\cline { 2 - 3 } & TSH $(7) \dagger$ & Saline (6) & saline \\
\hline $\begin{array}{l}\text { Clearance before } \\
\text { injection }\end{array}$ & $\mathrm{ml} / \mathrm{min}$ & $\mathrm{ml} / \mathrm{min}$ & $\mathrm{ml} / \mathrm{min}$ \\
$\begin{array}{l}\text { Clearance after } \\
\text { injection }\end{array}$ & $0.402 \pm 0.059 \ddagger$ & $0.446 \pm 0.116$ & \\
$\begin{array}{l}\text { Change in clearance } \\
\text { p }\end{array}$ & $\begin{array}{c}0.318 \pm 0.037 \\
0.084 \pm 0.041\end{array}$ & $0.447 \pm 0.105$ & \\
\hline & $>0.2$ & $>0.001 \pm 0.026$ & -0.085 \\
& & $>0.9$ & $>0.1$ \\
\hline
\end{tabular}

* Unidirectional clearance was considered to be the mean of the observed net clearances determined during the first 10 minutes after isotope injection.

$t$ Value in parentheses indicates number of dogs in each group.

$¥$ Mean \pm standard error of mean.
TABLE IV

Response of thyroidal protein-bound and inorganic iodide release to various $T S H$ dose levols*

\begin{tabular}{|c|c|c|c|c|c|}
\hline \multirow{2}{*}{$\underset{\text { ment }}{\text { Experi- }}$} & \multirow[b]{2}{*}{ Parameter } & \multicolumn{4}{|c|}{ TSH dose (U.S.P. U) } \\
\hline & & 0.001 & 0.005 & 0.05 & 5.0 \\
\hline 216 & $\begin{array}{l}\mathrm{PB}^{131} \mathrm{I} \\
{ }_{131} \mathrm{ID}^{-} \\
125 \mathrm{I}^{-}\end{array}$ & & & & $\begin{array}{l}+0.65 \\
+0.96 \\
+4.17\end{array}$ \\
\hline 221 & $\begin{array}{l}\mathrm{PB}^{181} \mathrm{I}^{1} \\
{ }^{131 \mathrm{I}_{\mathrm{D}}^{-}} \\
{ }^{126 \mathrm{I}^{-}}\end{array}$ & & & $\begin{array}{r}+0.10 \\
+0.11 \\
+1.49\end{array}$ & \\
\hline 222 & $\begin{array}{l}\mathrm{PB}^{181 I^{-}} \\
{ }^{181} \mathrm{ID}^{-} \\
125 \mathrm{I}^{-}\end{array}$ & & $\begin{array}{l}+0.015 \\
-0.02 \\
+0.28\end{array}$ & $\begin{array}{r}+0.05 \\
+0.09 \\
+0.84\end{array}$ & \\
\hline 226 & $\begin{array}{l}\mathrm{PB}^{131} \mathrm{I} \\
{ }_{131} \mathrm{ID}^{-} \\
125 \mathrm{I}^{-}\end{array}$ & $\begin{array}{l}-0.03 \\
-0.015 \\
-0.25\end{array}$ & $\begin{array}{c}0 \\
0 \\
+0.06\end{array}$ & $\begin{array}{r}+0.09 \\
+0.08 \\
+1.58\end{array}$ & \\
\hline
\end{tabular}

* Response indicated as the increase in mean veno-arterial concentra tion difference $(\% \mathrm{D} / \mathrm{L})$ for the 15 - to 30 -minute period after TSH injection over that of the 15 -minute period preceding the injection. A negative value indicates a decrease in the concentration difference after TSH.

$\mathrm{PB}^{181}{ }^{18}=$ protein-bound-131I ${ }^{131} \mathrm{ID}^{-}=$iodide released from the gland that originated from deiodination of organic precursors.

travenous doses of $\mathrm{TSH}$ ranging from 0.001 to $15.0 \mathrm{U}$ were given at 30 -minute intervals in the following sequence : $\operatorname{dog} 216,5$ and $15 \mathrm{U}$; $\operatorname{dog} 221$, $0.05,0.5$, and $5.0 \mathrm{U}$; $\operatorname{dog} 222,0.005,0.05$, and $5.0 \mathrm{U}$; $\operatorname{dog} 226,0.001,0.005$, and $0.05 \mathrm{U}$. The average veno-arterial concentration difference was determined for the 15-minute interval preceding each injection and the 15- to 30-minute interval after each TSH injection. The latter period represents an interval in which the release of both transported iodide and iodide generated in the gland as well as protein-bound iodine are readily discernible after large doses of TSH. Results are reported as the increase in the mean concentration difference of each post-TSH period over that of the control period preceding the injection (Table IV). Values are given for each dose up to that which first produced a clearly discernible release of radioiodide from one source or the other.

No dose-dependent dissociation of release of transported iodide from that of iodide originating from organic precursors or protein-bound iodine could be detected. Doses below $0.05 \mathrm{U}$ were without effect on any of these parameters, whereas. higher doses produced release of iodide from both sources as well as protein-bound iodine.

\section{Discussion}

The results of the group I experiments are consistent with earlier reports $(1,2,4,5)$ of release 
into thyroid venous blood of inorganic iodine shortly after TSH administration. Furthermore, these results demonstrate in a single preparation that when organic binding is blocked, there is simultaneous release of iodide originating from both iodide recently trapped from the circulation and present in the gland in inorganic form (transported iodide), and iodide derived from intrathyroidal organic precursors.

The release of iodide produced in the gland is sustained and parallels the release of protein-bound iodine. The release of transported iodide is transient, the thyroid venous concentration promptly rising to a peak and then falling to levels approaching that observed in the systemic blood. This release of transported iodide may be reflected in the initial $\mathrm{TSH}$-induced fall in the $\mathrm{T} / \mathrm{S}$ ratio observed in intact and hypophysectomized rats (8) and the early fall in thyroid radioiodide content after TSH (binding blocked) reported in rats and man (9). The group ID experiment demonstrates that the latter phenomenon also occurs in the dog.

It has been suggested (5) that after TSH administration, iodide generated by deiodination of iodotyrosines enters the thyroid "iodide space," thus tending to increase the $\mathrm{T} / \mathrm{S}$ stable iodide ratio. If the rate of entry of iodide from the circulation remained constant, this would result in a release of iodide from the gland. The release of trapped iodide would be similar to the washout of trapped iodide from the blocked gland observed when stable iodide is given (10), except that the source of the new iodide would be from within the gland itself. Such a theory presumes that 1) iodide derived from organic precursors is at least in part exchangeable with transported iodide, and 2) that the increment of the former accumulating in the gland would be of sufficient magnitude to produce measurable release of the latter into thyroid venous blood.

The first of these premises was examined in the group IB experiments in which an estimation was made of the quantity of radioactive iodide discharged in the first sample after thiocyanate or perchlorate injection and which could be ascribed to the effect of these ions on the trapping mechanism. Within 35 minutes after TSH, there was a fourfold increase in the proportion of ${ }^{131} \mathrm{I}$ in the thyroidal iodide exchangeable with blood iodide, the ratio of ${ }^{125} \mathrm{I}^{-} /{ }^{131} \mathrm{I}$ - being $82 \%$ of the same value in arterial blood before TSH and $21 \%$ after TSH. No fall in the ${ }^{125} \mathrm{I}^{-} /{ }^{131} \mathrm{I}^{-}$ratio was seen in three animals to which no TSH was given.

Rosenberg, Athans, Behar, and Ahn (11) measured the specific activity of iodide in thyroid venous blood after perchlorate injection in methimazole-treated dogs 40 to 70 minutes after TSH injection and in animals not receiving TSH. They found the specific activity to be $86 \%$ of the corresponding arterial value in animals not receiving $\mathrm{TSH}$ and $16 \%$ of the arterial value in TSHtreated animals and concluded that the fall in specific activity under these conditions was consistent with a mixing of unlabeled iodide coming from deiodination of organic precursors with iodide that had entered the gland from the circulation. Since in the present study the ${ }^{131} \mathrm{I}$ was given 3 to 7 days in advance of the experiments, it must have been approaching equilibrium with the stable thyroid iodine, so that the ${ }^{125} \mathrm{I}^{-} /{ }^{131} \mathrm{I}^{-}$ratio would reflect the specific activity of the ${ }^{125} \mathrm{I}^{-}$discharged by thiocyanate or perchlorate. The data support the idea that when organic binding is blocked, an appreciable portion of the iodide derived from inorganic precursors is exchangeable with blood iodide.

In two recent reports $(12,13)$ of studies of rat thyroid homogenates, it was concluded that there is a second thyroid iodide pool that is sequestered and largely immiscible with the pool of transported iodide, the size of this second pool being unaffected by compounds that block the trapping of transported iodide or its incorporation into organic compounds. It was suggested that this second pool is derived from deiodination of organic compounds (12). The data from the present study suggest that the previously reported (11) reduction in specific activity of iodide discharged by perchlorate from the thyroids of $\mathrm{TSH}$-injected animals is attributable to the entry of iodide produced by deiodination into the pool of perchloratedischargeable iodide. However, these data do not indicate whether some of the iodide originating from organic precursors may also have entered a pool of nondischargeable iodide or even have been reincorporated into organic compounds despite the administration of methimazole. Only exchanges of iodide between gland and circulation were examined, and no attempt was made to measure the quantity of inorganic iodide of intrathyroidal origin remaining in the gland after the final large 
dose of perchlorate. To determine, by the methods used in this study, whether any iodide derived from deiodination entered a perchlorate-insensitive pool, one would need to know the quantity of $\mathrm{I}_{\mathrm{D}^{-}}$- formed during the experimental period as well as the quantity that was discharged by perchlorate.

If iodide generated by deiodination of iodotyrosines is exchangeable with iodide entering from the circulation, then the possibility exists that the increment of thyroidal iodide may be of sufficient magnitude to cause the equilibrium $\mathrm{T} / \mathrm{S}$ stable iodide ratio to be exceeded and result in a release of iodide into thyroid venous blood until equilibration has been re-established. To test this possibility, we created experimental conditions in which the increment of intraglandular iodide coming from organic precursors after $\mathrm{TSH}$ injection would have been negligible relative to the quantity of iodide already present in the gland. This was accomplished in the group IC experiments by elevating the plasma concentration of iodide. It is known that, within a wide range of plasma iodide concentration, the glandular content of trapped iodide increases with increasing plasma iodide concentration $(14,15)$. Plasma iodide levels 10 to 100 times normal were achieved, and one would predict, on the basis of a displacement theory, that the accumulation of iodide coming from organic precursors after TSH stimulation would not appreciably affect the existing equilibrium of iodide between thyroid and circulation. Therefore, no measurable enhancement of transported, ${ }^{125} \mathrm{I}-\mathrm{la}$ beled iodide release would occur. However, neither the shape nor the magnitude of the transported iodide release curve was changed. Thus, it appears that a quantity of organic precursorderived iodide, presumably similar in magnitude to that seen in group IA and IB experiments, was associated with a release of transported iodide that was 10 to 100 times greater than in the experiments in which no carrier iodide was given. On the basis of these findings, the concept of a simple displacement mechanism is no longer tenable as an explanation for the release of transported iodide after TSH stimulation.

Neither can the release of transported iodide be explained by a change in the rate at which circulatory iodide enters the thyroid. When unidirectional clearance of iodide by the thyroid was estimated (group II experiments) both before and
15 to 30 minutes after TSH or saline injection, no significant difference in change in clearance could be observed between the saline controls and the TSH group. The post-TSH clearance was measured at a time during or just after the most vigorous transported radioiodide release.

The question of multifocal versus a unifocal action of TSH can be raised with regard to the effects of TSH upon release of transported iodide and iodide produced in the gland, i.e., whether the release of transported iodide is dependent upon the process of deiodination and formation of iodide from organic compounds. The group III experiments have a bearing on this point. An attempt was made to find a threshold dose of TSH at which a dissociation of its effects upon release of protein-bound iodine, iodide produced in the gland, and transported iodide might occur. At doses below $50 \mathrm{mU}$, no distinct enhancement of release in any of these parameters occurred, whereas doses of $50 \mathrm{mU}$ or more produced enhanced release of all three. Since no dissociation of responses could be observed, we can conclude only that if the release of transported iodide and the release of iodide generated from organic precursors after TSH stimulation are independent and unrelated effects of TSH, they occur at the same level of TSH activity.

The mechanism by which TSH induces a thyroidal release of transported iodide and the question of whether this is in any way mediated by the intraglandular generation of iodide from organic stores remain to be elucidated. The latter problem might be clarified by studies of goitrous cretins with dehalogenase deficiencies or by animal studies in which deiodination has been inhibited.

\section{Summary}

The thyrotropin (TSH)-enhanced release of inorganic iodine from the methimazole-blocked thyroid has been studied in the dog by thyroid venous cannulation and differential isotopic labeling of circulating iodide and glandular organic iodine with ${ }^{125} \mathrm{I}$ and ${ }^{131} \mathrm{I}$. TSH injection resulted in simultaneous glandular release of iodide derived from organic precursors and of iodide that had been newly transported into the gland from the circulation. At least some of the iodide derived from organic precursors was readily miscible 
within the gland with iodide trapped from the circulation as judged by ${ }^{125} \mathrm{I} /{ }^{131} \mathrm{I}$ ratios in iodide discharged by perchlorate or thiocyanate before and after TSH administration. The fraction of the trapped circulatory iodide in the gland that was released after TSH was not decreased in the presence of greatly elevated plasma iodide concentrations, suggesting that the mechanism of release was not simple displacement of trapped circulatory iodide by iodide produced in the gland. TSH rapidly induced a marked fall in the total glandular content of transported radioiodide, but did not significantly reduce the rate of unidirectional clearance of circulating iodide by the thyroid. The smallest dose of TSH that induced detectable glandular release of transported iodide was the same as that which produced release of iodide from glandular organic precursors and release of protein-bound iodine.

\section{References}

1. Rosenberg, I. N., J. C. Athans, and A. Behar. Effect of thyrotropin on the release of iodide from the thyroid. Endocrinology 1960, 66, 185.

2. Nagataki, S., K. Shizume, K. Matsuda, and J. Ishii. Release of inorganic iodine from thyroid gland in initial phase of TSH action. Proc. Soc. exp. Biol. (N. Y.) 1959, 102, 765.

3. Rosenberg, I. N., J. C. Athans, and G. H. Isaacs. Studies on thyroid iodine metabolism. Recent Progr. Hormone Res. 1965, 21, 33.

4. Nagataki, S., K. Shizume, and S. Okinaka. Effect of thyrotropin on the metabolism of iodide ${ }^{121}$ in the thyroid gland. Endocrinology 1961, 69, 199.
5. Rosenberg, I. N., J. C. Athans, C. S. Ahn, and A. Behar. Thyrotropin-induced release of iodide from the thyroid. Endocrinology 1961, 69, 438.

6. Wollman, S. H., and F. E. Reed. Transport of radioiodide between thyroid gland and blood in mice and rats. Amer. J. Physiol. 1959, 196, 113.

7. Wollman, S. H., and F. E. Reed. Kinetics of accumulation of radioiodine by thyroid gland: short time intervals. Amer. J. Physiol. 1962, 202, 182.

8. Halmi, N. S., D. K. Granner, D. J. Doughman, B. H. Peters, and G. Müller. Biphasic effect of TSH on thyroidal iodide collection in rats. Endocrinology $1960,67,70$.

9. Rosenberg, I. N., C. S. Ahn, and M. H. Chalfen. Effect of thyrotropin upon release of iodide from human and rat thyroid. J. clin. Endocr. 1961, 21, 554.

10. Stanley, M. M., and E. B. Astwood. The accumulation of radioactive iodide by the thyroid gland in normal and thyrotoxic subjects and the effect of thiocyanate on its discharge. Endocrinology 1948, 42, 107.

11. Rosenberg, I. N., J. C. Athans, A. Behar, and C. S. Ahn. Thyrotropin-induced release of iodide from the thyroid in Advances in Thyroid Research. New York, Pergamon, 1961, p. 194.

12. Halmi, N. S., and R. Pitt-Rivers. The iodide pools of the rat thyroid. Endocrinology 1962, 70, 660.

13. Nagataki, S., and S. H. Ingbar. Demonstration of a second thyroidal iodide pool in rat thyroid glands by double isotope labeling. Endocrinology 1963, 73, 479.

14. VanderLaan, J. E., and W. P. VanderLaan. The iodide concentrating mechanism of the rat thyroid and its inhibition by thiocyanate. Endocrinology 1947, 40, 403.

15. Halmi, N. S. Thyroidal iodide trapping as influenced by serum iodide levels and thyrotropin. Endocrinology 1954, 54, 97. 